\title{
STUDY OF CAROTICO CLINOID FORAMEN IN DRY HUMAN SKULLS
}

\section{Vijayshree Muthukumar ${ }^{1}$, Komala Nanjundaiah ${ }^{* 2}$ Shailaja Shetty ${ }^{3}$.}

${ }^{1}$ MBBS, M S Ramaiah Medical College, Bangalore, Karnataka, India.

${ }^{2}$ Associate Professor, Department of Anatomy, M.S.Ramaiah Medical College, Bangalore, Karnataka, India.

${ }^{3}$ Professor and Head, Department of Anatomy, M.S.Ramaiah Medical College, Bangalore, Karnataka, India.

Back ground: The carotico clinoid foramen is formed by an osseous bridge between tip of the middle and anterior clinoid processes of the sphenoid bone and transmits one of the segments of internal carotid artery (ICA).

Context: The existence of a bony or osseous carotico clinoid foramen may cause compression, tightening or stretching of the ICA, especially of the clinoidal segment and cause complications in regional surgery.

Purpose: The present study is an effort to study the carotico clinoid foramen in skulls and observe various parameters like presence or absence, unilateral or bilateral, complete or incomplete, extent, dimensions of the ligament, dimensions of the foramen and sexual dominance.

Results: Presence of complete foramen was found in $12 \%$ and incomplete foramen was $26 \%$. The mean width and thickness of the ligaments was found to be greater on the left side and greater in males. The size of the foramen was found to be more on the left side and in males. Complete foramina were found to be more in males while incomplete foramina were found equally in both sexes. Unilateral foramen were found to be more in females while bilateral foramina were found to be more in males.

Conclusion: Considering the fact that most of the anatomy text books do not provide a detailed description of the carotico clinoid ligament or foramen, the present study proves especially relevant to neurosurgeons in day to day clinical practice.

Implication: Knowledge of the prevalence of carotico clinoid foramen helps the neuro-surgeons for pre-operative scanning and precautions can be taken to prevent fatal complications during surgery. Further, removal of the anterior clinoid process is an important step in regional surgery, for which additional risk is involved. Therefore detailed anatomical knowledge of the carotico clinoid foramen is of utmost importance, to increase the success of regional surgeries.

KEY WORDS: carotico clinoid foramen, clinoid process, internal carotid artery, clinoidectomy, interclinoid foramen.

Address for Correspondence: Dr. Komala Nanjundaiah, Associate Professor, Department of Anatomy, M.S.Ramaiah Medical College, M.S.R Nagar, Bangalore 560054, Karnataka, India.

E-Mail: komas2001@yahoo.com

\begin{tabular}{|l|l|}
\multicolumn{3}{|c|}{ Access this Article online } \\
\hline Quick Response code & $\begin{array}{l}\text { Web site: International Journal of Anatomy and Research } \\
\text { ISSN 2321-4287 } \\
\text { www.ijmhr.org/ijar.htm }\end{array}$ \\
\cline { 2 - 3 } & \multicolumn{2}{|c|}{$\begin{array}{l}\text { Accepted: 20 Oct } 2017 \\
\text { Dol: } 10.16965 / \text { ijar.2017.425 }\end{array}$} & $\begin{array}{l}\text { Received: 18 Aug 2017 } \\
\text { Reer Review: 18 Aug 2017 }\end{array}$ & $\begin{array}{l}\text { Published (O): 01 Nov } 2017 \\
\text { Published (P): 01 Nov } 2017\end{array}$ \\
\hline
\end{tabular}

\section{INTRODUCTION}

The carotico clinoid foramen, first described by Henle (1855), is formed by an osseous bridge between the tip of the middle and anterior clinoid processes of the sphenoid bone [1].

The sella turcica is a saddle shaped depression on intracranial surface of body of sphenoid bone. There are three Clinoid processes present on 
either side of sella turcica: The anterior clinoid processes are formed by the medial and anterior prolongations of the lesser wing of the sphenoid bone. The posterior clinoid processes are present at the end of the dorsum sellae. The middle clinoid processes are present on either side of tuberculum sellae [2]. The carotico clinoid ligament connecting anterior and middle clinoid processes sometimes get ossified forming the carotico clinoid foramen which transmits one of the segments of internal carotid artery. Ossification of interclinoid ligament that connects the anterior and posterior clinoid processes is termed as interclinoid osseous bridge or sella turcica Bridge [3]. Rarely, the three processes fuse with each other [4]. These bridges are related to the cavernous sinus, internal carotid artery, and pituitary gland. The existence of a bony or osseous carotico clinoid foramen may cause compression, tightening or stretching of the internal carotid artery, especially of the clinoidal segment and cause complications in regional surgery. Variations in sellar region like the interclinoid bar and the carotico clinoid foramen may cause difficulty for clinoidectomy procedures especially in the presence of an aneurysm and in surgical management while dealing with the vascular, neoplastic or traumatic lesions of the central skull base [5]. Considering its significance in various neurological disorders and neurosurgeries, the present study was undertaken to determine the prevalence and study the morphology of the carotico clinoid foramen in adult human skulls.

\section{MATERIALS AND METHODS}

This cross sectional study was conducted on 100 dry unknown human skulls from the department of Anatomy of M S Ramaiah Medical College and Sapthgiri Institute of medical Sciences. Male and female skulls were identified based on forensic anthropometry ${ }^{(6)}$. Based on the literature survey in a study conducted by Dr S D Desai "study of carotico clinoid foramen in dry human Skulls of north interior Karnataka"(7), it was found that the prevalence of CCF was $37 \%$. So with an absolute precision of $9.5 \%$ and $95 \%$ confidence level, the sample size required for the present study was estimated to be 100 . The calvarias were removed. The skulls which were well ossi fied and had intact clinoid processes were included while fragmented, broken skulls were excluded from the study. The skulls were observed under daylight and photographed. The morphometry was performed using digital Vernier callipers. The following parameters were recorded:

1) Presence/absence of the foramen

2) Complete/incomplete foramen

3) Unilateral/bilateral foramen

4) Dimensions of the foramen (maximum and minimum diameters of the foramen)

5) Dimensions of the ligament (width and thickness of the ligament)

6) Sex of the skull.

For the classification of the interclinoid bars, the method proposed by Rani Archana et al [8] and the method proposed by Keyers [9] were used:

Rani Archana et al [8] classified interclinoid bars into four types:

Type I: - Bridge present between anterior and middle clinoid process (carotico clinoid foramen).

Type II: - Bridge between anterior, middle and posterior clinoid process.

Type III (Sella Turcica Bridge):- Bridge between anterior and posterior clinoid process.

Type IV: - Bridge between the middle and posterior clinoid process.

Keyers [9] further classified each type of bridge into three subtypes depending upon the extent of fusion between the bony bars arising from the respective clinoid process.

a. Complete type: - A complete fusion between two bony bars.

b. Contact type: - Presence of a dividing line or suture between bony bars.

c. Incomplete type: - If a spicule of bone was extending from one clinoid process towards the other with a gap in between.

The data was analysed statistically with IBM SPSS Statistics.Graphs and tables were generated using Microsoft office word and excel software.

\section{RESULTS}

Incidence of the type I foramen (Fig 1B) is 32\%, the incidence of the type II foramen (Fig 1C) is $2 \%$, type III foramen (Fig 1D) is again $2 \%$ and 
Vijayshree Muthukumar, Komala Nanjundaiah, Shailaja Shetty. STUDY OF CAROTICO CLINOID FORAMEN IN DRY HUMAN SKULLS.

type IV foramen were not encountered. 64 skulls showed no caroticoclinoid foramen. (Fig 1A). The second type of classification showing complete(Fig 2A), contact (Fig 2B) and incomplete foramen (Fig 2C) were also considered for description.

Fig. 1-A: Absent carotico clinoid ligament. The anterior, middle and posterior clinoid process (arrows) are free.

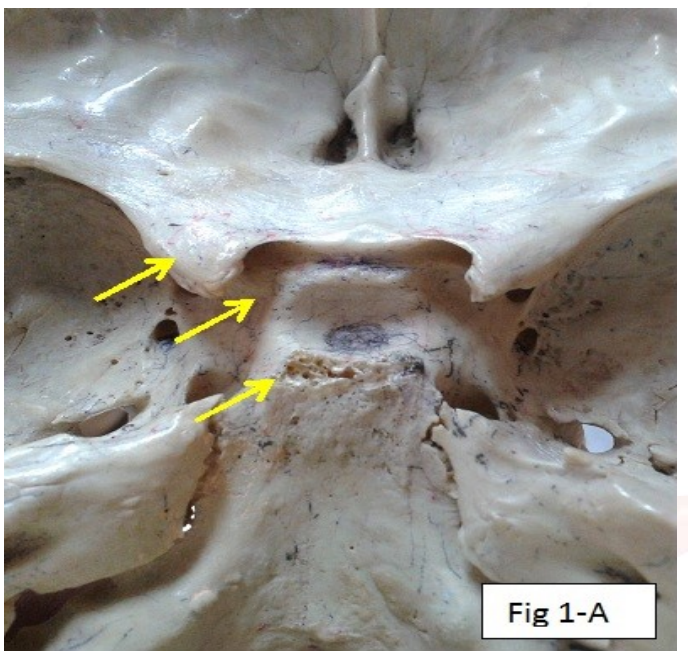

Fig. 1-B: Type I: - Bridge present between anterior and middle clinoid process (caroticoclinoid foramen shown by single arrow).

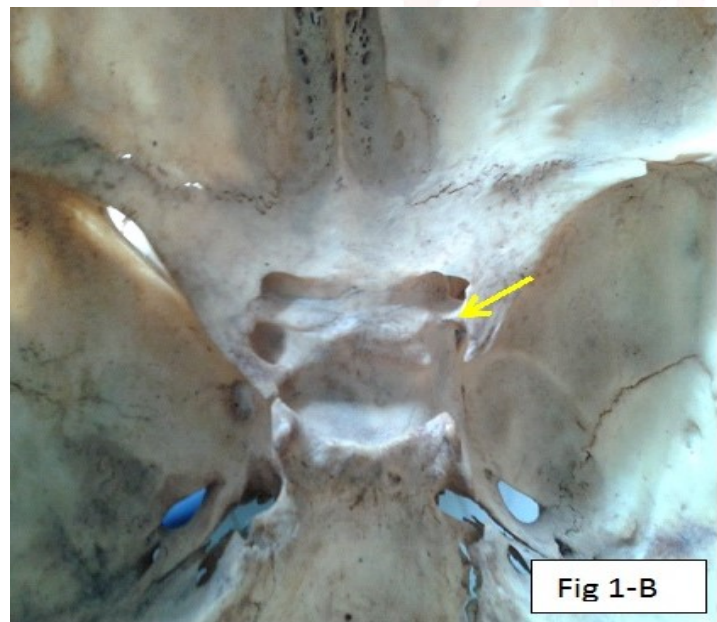

Fig 1-C: Type II: - Bridge between anterior, middle and posterior clinoid process. (shown by single arrow)

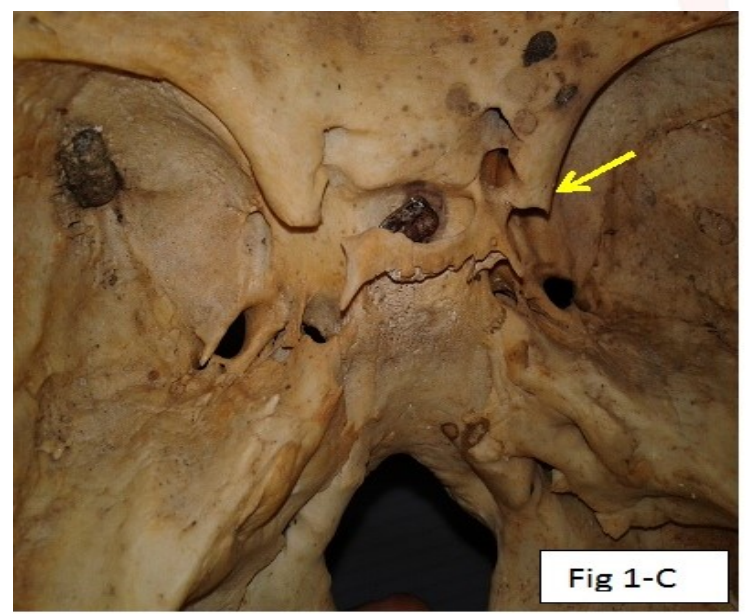

Fig. 1-D: Type III (Sella Turcica Bridge):- Bridge between anterior and posterior clinoid process. The figure shows bilateral type III sella Turcica Bridge.
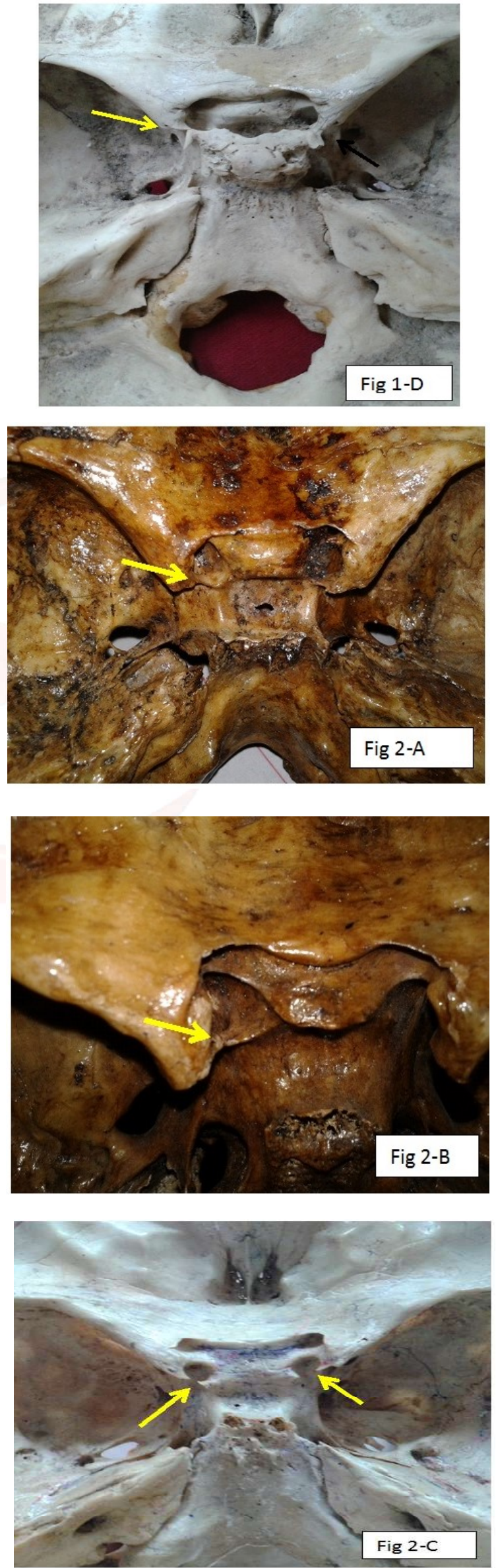
Various types of carotico clinoid ligaments, dimensions of the ligament and the dimensions of the foramen are tabulated as follows.

Table 1: Presence of various types of carotico clinoid ligaments in both sexes.

\begin{tabular}{|c|c|c|c|}
\hline Type of carotico clinoid ligament & Males & Females & Total \\
\hline Complete- Unilateral Right & $1 \%$ & $0 \%$ & $1 \%$ \\
\hline Complete - Unilateral Left & $1 \%$ & $1 \%$ & $\mathbf{2} \%$ \\
\hline Complete- Bilateral & $4 \%$ & $3 \%$ & $7 \%$ \\
\hline Incomplete- Unilateral Right & $5 \%$ & $6 \%$ & $11 \%$ \\
\hline Incomplete- Unilateral Left & $2 \%$ & $3 \%$ & $5 \%$ \\
\hline Incomplete- Bilateral & $5 \%$ & $3 \%$ & $8 \%$ \\
\hline $\begin{array}{c}\text { Bilateral- one side complete and } \\
\text { other side incomplete }\end{array}$ & $1 \%$ & $1 \%$ & $2 \%$ \\
\hline
\end{tabular}

Table 2: Dimensions of the ligament.

\begin{tabular}{|c|c|c|c|}
\hline Parameter & $\begin{array}{c}\text { Mean value } \\
\text { (in mm) }\end{array}$ & $\begin{array}{c}\text { Maximum value } \\
\text { (in mm) }\end{array}$ & $\begin{array}{c}\text { Minimum value } \\
\text { (in mm) }\end{array}$ \\
\hline Width Of The Ligament- Right & 3.03 & 4 & 1.96 \\
\hline Width Of The Ligament- Left & 3.22 & 3.79 & 1.85 \\
\hline Thickness Of The Ligament- Right & 1.45 & 1.95 & 0.78 \\
\hline Thickness Of The Ligament- Left & 1.59 & 1.8 & 1.3 \\
\hline
\end{tabular}

Table 3: Dimensions of the foramen.

\begin{tabular}{|c|c|c|c|}
\hline Parameter & $\begin{array}{c}\text { Mean value } \\
\text { (in mm) }\end{array}$ & $\begin{array}{c}\text { Maximum value } \\
\text { (in mm) }\end{array}$ & $\begin{array}{c}\text { Minimum value } \\
\text { (in mm) }\end{array}$ \\
\hline Maximum Diameter- Right & 5.49 & 6.79 & 4.46 \\
\hline Maximum Diameter- Left & 5.65 & 6.19 & 5.29 \\
\hline Minimum Diameter- Right & 4.67 & 6.36 & 3.49 \\
\hline Minimum Diameter- Left & 4.64 & 5.19 & 4.29 \\
\hline
\end{tabular}

\section{DISCUSSION}

The anterior and middle clinoid processes in the living are normally linked by a ligament which is not seen in the dry skull. If it does not ossify, it leaves behind a space between the anterior and middle clinoid process called the clinoid space. If the ligament ossifies it forms a foramen through which the internal carotid artery courses to supply the brain. This foramen is called "foramen clinoideo caroticum", the carotico clinoid foramen [10]. The ossification of fibrous ligaments is considered a normal physiological process that occurs with age [1]. However this process is an exception when one considers the formation of the Carotico clinoid foramen. The presence of this foramen has been demonstrated in foetal and skulls of children in previous studies [11]. Carotico clinoid foramen becomes exceedingly important for neurosurgeons as fatal complications may arise during skull base surgery if relevant pre-operative scanning with special relevance to this structure is not done
Clinoidectomy is an essential step in skull base surgeries and the osseous carotico clinoid foramen is an underestimated structure which has important neuronal and vascular relations [12]. Although there are previous studies on the prevalence of the foramen, no literature is available on the morphometric measures of the ligament and foramen or relating the prevalence of the foramen in the two sexes.

Table 4: Comparison of incidence of carotico clinoid foramen in other studies on Indian skulls.

\begin{tabular}{|c|c|c|c|c|}
\hline Author & Year & $\begin{array}{c}\text { No of skulls } \\
\text { observed }\end{array}$ & Incidence & Region of study \\
\hline Desai S et al [7] & 2010 & 223 & $37.19 \%$ & Karnataka \\
\hline Bindu A et al [13] & 2011 & 70 & $15.72 \%$ & Mumbai \\
\hline Sanobar I et al [12] & 2011 & 100 & $24 \%$ & Aurangabad \\
\hline Kanjiya D et al [14] & 2012 & 200 & $14.50 \%$ & Gujarat \\
\hline Magadum A [15] & 2012 & 50 & $3 \%$ & Belgaum \\
\hline Present study & 2013 & 100 & $36 \%$ & Karnataka \\
\hline
\end{tabular}

Table 5: Comparison of incidence of carotico clinoid foramen in other studies on various populations.

\begin{tabular}{|c|c|c|c|c|}
\hline Author & Year & Sample size & Population & Incidence \\
\hline Keyers et al [9] & 1935 & 2187 & American & $27.50 \%$ \\
\hline Inoue et al [16] & 1990 & 50 & American & $25 \%$ \\
\hline Erturk et al [1] & 2003 & 171 & Turkish & $23.68 \%$ \\
\hline Lang et al [4] & 1977 & 165 & German & $18.20 \%$ \\
\hline Desai S et al [7] & 2010 & 223 & Indian & $37.19 \%$ \\
\hline Present study & 2013 & 100 & Indian & $36 \%$ \\
\hline
\end{tabular}

Thus amongst Indians a higher incidence is seen in South India (Karnataka) compared to North India (Gujarat). Incidence in Karnataka is more than that found in Maharashtra or Gujarat. Thus amongst the various populations Indians have the highest incidence (South India). The presence of carotico clinoid foramen causes morphological changes in the internal carotid artery traversing the canal which in turn may cause compression of the cavernous sinus because of its medial position. The presence of the carotico clinoid foramen may even cause a headache in patients due to compression of the internal carotid artery in this foramen. After removal of the anterior clinoid process, the triangular clinoid space is observed. This space varies according to dimension of the anterior clinoid process and the internal carotid artery. Further, removal of the anterior clinoid process is one of the most critical procedures to the successful and safe management of ophthalmic segment aneurysms and tumours located in the paraclinoid region and cavernous sinus [12]. 


\section{CONCLUSION}

The presence of the carotico clinoid foramen causes morphological changes in the internal carotid artery in almost all cases. Changes in internal carotid artery may cause compression of the cavernous sinus because of its medial position and cause complications in regional surgery. Variations in sellar region like the interclinoid bar and the carotico clinoid foramen may cause difficulty for clinoidectomy procedures especially in the presence of an aneurysm and in surgical management while dealing with the vascular, neoplastic or traumatic lesions of the central skull base.

Considering the fact that the anatomy text books do not provide a detailed description of the carotico-clinoid ligament or foramen, the present study proves especially relevant to neuro surgeons in day to day clinical practice. Further, removal of the anterior clinoid process is an important step in regional surgery, for which additional risk is involved. Therefore detailed anatomical knowledge of the carotico clinoid foramen is of utmost importance, to increase the success of regional surgeries and diagnostic evaluations.

\section{ABBREVIATIONS}

\section{ICA - Internal Carotid Artery}

\section{ACKNOWLEDGEMENTS}

Dr.Jayanthi Professor, Department of Anatomy, Sapthagiri Institute of medical Sciences. Ms Radhika, statistician, Department of Community Medicine The first year MBBS students of M S Ramaiah medical college and Sapthagiri Institute of medical Sciences for lending their skulls for the research.

\section{Conflicts of Interests: None}

\section{REFERENCES}

[1]. Erturk M, Kayalioglu G. Anatomy of the clinoidal region with special emphasis on the caroticoclinoid foramen and interclinoid osseous bridge in a recent Turkish population. Neurosurg Rev $2004 ; 27(1): 22-26$.
[2]. Breathnach AS. Frazer's Anatomy of Human Skeleton in sphenoid. J \& A Churchil Ltd. London 1965;6:200-205.

[3]. Williams P, Bannister L. Gray's Anatomy in skull Churchill Livingstone, New York 2000;38:547-612.

[4]. Lang J. Structure and postnatal organization of here to fore uninvestigated and infrequent ossifications of the sella turcica region. Acta Anat 1977;99:121139.

[5]. Rengachari S, Ellenbogen R. Intracranial aneurysm. In: Principles of Neurosurgery. USA: Elsevier Mosby;2005;2:222-25.

[6]. Iscan MY. forensic anthropology of sex and body size. Forensic science international. 2005;147(2) :107-12.

[7]. Dr Desai S D , Dr Sreepadma S. Study of carotico clinoid foramen in dry human skulls of north interior Karnataka National Journal of Basic Medical Sciences 2010;1(2): 60-64.

[8]. Archana R, Anita R. Incidence of osseous interclinoid bars in Indian population Surg Radiol Anat. 2010;32(4):383-87.

[9]. Keyers J. Observations on four thousand optic foramina in human skulls of known origin Arch Ophthalmol. 1935;13:538-68.

[10]. DubRul E. Oral anatomy in the skull. J of Anatomy. 1990;169:266-67.

[11]. Kier E. Embryology of the normal optic canal and its anomalies. An anatomic and roentgenographic study. Invest. Radiol, 1996;1:346-62.

[12]. Shaikh S I,Ukey R K. Study of carotico-clinoid foramen in dry human skulls of aurangabad district International Journal of Basic Medical Sciences 2013;4(2):148-54.

[13]. Aggrawal B. Ossified caroticoclinoid ligament of sphenoid bone Bombay Hospital Journal. 2011;53(4):743-46.

[14].Kanjiya D, Tandel M. Incidence of ossified interclinoid bars in dry human skulls of Gujarat state International Journal of Biomedical and Advance Research 2012;03(12):874

[15]. Magadum A. A Study Of Caroticoclinoid Foramen In The South Indian Skulls: incidence, Morphometry And Its Clinical Correlations. biomirror, 2012; 3(05):1-3.

[16]. Inoue T, Rhoton A. Surgical approaches to the cavernous sinus: a microsurgical study. Neurosurgery1990;26:903-32.

How to cite this article: Vijayshree Muthukumar, Komala Nanjundaiah, Shailaja Shetty. STUDY OF CAROTICO CLINOID FORAMEN IN DRY HUMAN SKULLS. Int J Anat Res 2017;5(4.2):4630-4634. DOI: 10.16965/ijar.2017.425 